A review of research into automation in tourism:

Launching the Annals of Tourism Research Curated Collection on Artificial

Intelligence and Robotics in Tourism

Iis Tussyadiah

Professor of Intelligent Systems in Service

School of Hospitality and Tourism Management

University of Surrey

Guildford, GU2 7XH, United Kingdom

Email: i.tussyadiah@surrey.ac.uk

Accepted for publication in

Annals of Tourism Research

February 4, 2020 


\title{
A review of research into automation in tourism: Launching the Annals of Tourism Research Curated Collection on Artificial Intelligence and Robotics in Tourism
}

\begin{abstract}
Driven by the advancements in artificial intelligence (AI) and its related technologies, the application of intelligent automation in travel and tourism is expected to increase in the future. This paper unpacks the need to shape an automated future of tourism as a social phenomenon and an economic activity, hence contributes to theory and practice by providing directions for future research in this area. Four research priorities are suggested: designing beneficial AI, facilitating adoption, assessing the impacts of intelligent automation, and creating a sustainable future with artificial intelligence. Research in these areas will allow for a systematic knowledge production that reflects a concerted effort from the scientific community to ensuring the beneficial applications of intelligent automation in tourism. The article also launches the Annals of Tourism Research Curated Collection on Artificial Intelligence and Robotics. The Collection contains all past articles published in Annals of Tourism Research on the topic, and continues to grow as new articles are added. Keywords: artificial intelligence; intelligent automation; automated tourism; service robots; research agenda
\end{abstract}




\section{A review of research into automation in tourism: \\ Launching the Annals of Tourism Research Curated Collection on Artificial Intelligence and Robotics in Tourism}

\section{Highlights}

- A research agenda on preparing tourism for a more automated future is proposed

- First: to explore requirements to design beneficial artificial intelligence

- Second: to find ways to facilitate adoption of intelligent automation in tourism

- Third: to fully assess the impacts of intelligent automation in tourism

- Last: to leverage artificial intelligence to create pathways to sustainable tourism 


\section{Introduction}

According to Schwab (2016), we are undergoing the fourth industrial revolution, an era characterized by breakthroughs in emerging technologies in such fields as robotics, artificial intelligence (AI), nanotechnology, quantum computing, the internet-of-things, fifthgeneration wireless technologies, and fully autonomous vehicles, all of which will affect how we create and distribute value, and will change the way we live, work, and interact (Schulze, 2019). Whereas the third industrial revolution was marked by disruption through adoption of smart and autonomous systems fueled by data and machine learning, in the fourth industrial revolution, machines are connected and communicate with one another, allowing systems to make decisions without human involvement. As a result, automation has become the key ingredient of the digital transformation occurring in many sectors. Automation does not imply simple replacement of human labor by machines, but the integration of machines into a self-governing system that can accomplish a process without human assistance (Addo \& Yagci, 2015).

Like any other sector, tourism too is facing a more automated future. Tourism suppliers have started using intelligent machines in their operations. After introducing an android robot called Spencer to guide passengers at Amsterdam Airport Schiphol in 2015 (KLM, 2015; 2016), KLM Royal Dutch Airlines' new robot, Care-E, an intelligent selfdriving trolley, was tested and rolled out in 2018 to help flight passengers haul their luggage to the gate (CNN, 2018). The first robot hotel, Henn na Hotel, opened in Huis Ten Bosch, an amusement park in Japan, in 2015 (Guardian, 2015). It has since expanded its operation to various locations elsewhere. The hotel properties employ dinosaur receptionists, robot porters, a cloakroom robot, and in-room personal assistants, to name a few. Although a fully robotic hotel such as this may still be a rare case today, hotels around the world have implemented intelligent automation for some of their customer-facing operations, such as 
autonomous check-ins, virtual personal assistants, and room delivery robots. Indeed, Ivanov and Webster (2019a; 2019b) suggested that with advancements in robotic technologies comes tremendous potential for various aspects of tourism services to be automated.

Some of the benefits of intelligent automation in travel and tourism are apparent (e.g., comfort, convenience, savings), but so are the concerns surrounding the transformation it would bring to people and society in general (Gurkaynak, Yilmaz, \& Haksever, 2016). An important realization emerging from the automation of tourism services is the (potential) loss of human contact throughout the tourism experience. This has significant implications for tourism and tourism studies on many levels. Tourism has been studied for its capacity to bring two entities together: the self and the others, and the hosts and the guests, albeit briefly. Critical to tourism studies is the dynamics of the two actors - tourists are influenced by the allure of destination qualities, often projected through marketing, and destinations long to be visited by curious tourists. Interactions between tourists and destinations, including guesthost relationships and, at times, conflicts, have been central to tourism research (Bimonte \& Punzo, 2016; Lin, Chen, \& Filieri, 2017). It is believed that meaningful tourist-host interactions, be they with local residents or tourism workers, are a source of tourist endearment, leading to tourist satisfaction and a positive attitude toward tourism destinations (Pizam, Uriely, \& Reichel, 2000; Prentice, Witt, \& Wydenbach, 1994). As new technologies have been developed for and implemented in tourism, research has shown how technologies can mediate and, to some extent, enhance tourism experiences by transforming tourist activities in — and interactions with — tourism destinations (Tussyadiah \& Fesenmaier, 2009). However, when automation enters the realm of tourism experiences and replaces interpersonal contact, the transformation will go beyond what has been theorized in the tourism literature thus far. 
Tourism researchers have started showing interest in the areas of artificial intelligence, robotics, and automation, although their contributions are still limited to descriptions of current applications and potential future implementations and impacts (Ivanov \& Webster, 2019a; 2019b; 2019c; Murphy, Gretzel, \& Pesonen, 2019; Murphy, Hofacker, \& Gretzel, 2017; Tung \& Law, 2017; Yeoman \& Mars, 2012). Specifically, because of the limited scope of implementation of intelligent automation in tourism and hospitality thus far, empirical studies are limited to analysis of online reviews (Tung \& Au, 2018) and experiments with second-hand experience of robots (Lu, Cai, \& Gursoy, 2019; Tussyadiah \& Park, 2018). Studies that more deeply explore the transformation that occurs in the ways tourism is performed, from the perspectives of those involved in the production and consumption of tourism, are still scant. Therefore, this paper calls for further research on intelligent automation in tourism by proposing key research priorities based on a review of the relevant literature and the trends in the integration of artificial intelligence and its related technologies in tourism. This paper unpacks the need to shape the (automated) future of tourism as a social phenomenon and an economic activity, hence contributing to providing directions for future research in this area. The sections that follow will first provide the definitions of artificial intelligence, robotics, the internet-of-things, and intelligent automation. These will be followed by a discussion about the benefits and challenges of intelligent automation application. Then, an agenda to guide future research on intelligent automation in tourism will be presented.

\section{Intelligent Automation in Tourism}

To delineate the scope of intelligent automation in this paper, definitions of artificial intelligence, robotics, and the internet-of-things will be provided before discussing intelligent automation and its applications in tourism. Although the fields of artificial intelligence and 
robotics were strongly connected at first, the two have diverged into separate streams of research, both of which have achieved enormous progress (Rajan \& Saffiotti, 2017). Most AI researchers are driven by top-down reasoning and ignore the physicality and embodiment of automation, leading to the development of 'disembodied AI' (e.g., Watson, Siri). Meanwhile, roboticists, generally from mechanical or electrical engineering backgrounds, adopt a more bottom-up approach, focusing on embodiment and sensorimotor functions. Efforts to reunite the two fields have resulted in innovative products requiring a combination of artificial intelligence and robotics, such as autonomous vehicles and service robots. To elucidate this development, separate definitions of artificial intelligence and robots, alongside relevant technological concepts around the internet-of-things, will be discussed.

\section{Definition and Classification}

Most definitions of artificial intelligence focus on it as a subfield of computer science or in terms of how machines can mimic human intelligence. The term "artificial intelligence" was first introduced in the 1950s by John McCarthy, who referred to it as "the science and engineering of making intelligent machines, especially intelligent computer programs” (McCarthy, 2007, n.p.). The Encyclopedia Britannica (n.d.) defines artificial intelligence as "the ability of a digital computer or computer-controlled robot to perform tasks commonly associated with intelligent beings" (n.p.). As suggested by Russell and Norvig (2010), the different approaches to defining artificial intelligence are based on two dimensions: thought-process-behavior and humanperformance-rationality. Artificial intelligence is thus defined as a system that thinks humanly, acts humanly, thinks rationally, or acts rationally. Six capabilities are required for machines to exhibit human behavior (act humanly), and these six capabilities represent the sub-disciplines of artificial intelligence: natural language processing (to communicate), knowledge representation (to store information), automated reasoning (to 
use stored information to draw conclusions), machine learning (to extrapolate patterns), computer vision (to perceive objects), and robotics (to manipulate objects and move about; Russell \& Norvig, 2010). Russell and Norvig preferred the rational-agent approach to defining AI systems (i.e., a system that acts rationally) because it is more amenable to scientific development than basing it on human performance.

Different capabilities of artificial intelligence have been suggested based on the human skills they can replicate. Huang and Rust (2018) suggested four different skills in service jobs: mechanical, analytical, intuitive, and empathetic intelligence. They further asserted that service automation can replace human labor because AI systems manage to do better than humans at tasks requiring these skills, starting from mechanical tasks and moving all the way up to empathetic tasks. 'Mechanical AI' deals with repetitive tasks, relies on observation to act and react repetitively, and thus ensures extreme consistency because it responds reliably to the environment. 'Mechanical AI' is typically considered 'weak AI' or 'narrow AI' in the literature (Nilsson, 2006). 'Analytical AI' performs complex, yet systematic, consistent, and predictable tasks, often involving processing a massive amount of data and learning from them (e.g., machine learning and data analytics). 'Intuitive AI' performs tasks that are complex, creative, chaotic, experiential, holistic, and contextual, requiring intuitive intelligence (e.g., personal travel concierge, life coach). Hence, it is considered 'strong AI.' Last, the most advanced artificial intelligence is 'empathetic AI,' which is often designed to look and act like a human and is able to provide psychological comfort for the well-being of its (human) users (e.g., Robot Sophia; Huang \& Rust, 2018).

The International Federation of Robotics (IFR) differentiates robots into industrial and service robots. According to the definitions from ISO 8373, an industrial robot is an "automatically controlled, reprogrammable multipurpose manipulator programmable in three or more axes," whereas a service robot is a robot "that performs useful tasks for humans or 
equipment excluding industrial automation applications" (International Federation of Robotics, 2018, n.p.; International Organization for Standardization, 2012, n.p.). A robot manipulator is also known as a robotic arm. Inherent to robots is a degree of autonomy, which, according to ISO 8373 , refers to the ability to perform intended tasks without human intervention based on current state and sensing (the immediate environment) (International Organization for Standardization, 2012). In the services management literature, a service robot is defined as technology that can perform physical tasks, operate autonomously without needing instruction, and [is] directed by computers without help from people (Colby, Mithas, \& Parasuraman, 2016). Thrun (2004) differentiated between professional service robots and personal service robots; the former assist people in the pursuit of professional goals, whereas the latter do so in domestic or recreational settings. In addition to service robots, Robotic Industries Association (2009) recognized collaborative robots (cobots) as a type of robot intended to physically interact with humans in a shared workspace.

Concerning intelligence, Lai, Lin and Wu (2018) defined an intelligent robot as a robot that "has its own environment perception ability and can connect perception and action through independent thinking and can make appropriate actions according to the external environment" (p. 450). Three elements distinguish intelligent robots from ordinary robots: sensory, movement, and thinking elements. First, the sensory element allows robots to recognize the state of the surrounding environment. This includes using noncontact sensors to sense vision, proximity, distance, and so on, and using contact sensors to sense force, pressure, and touch. Second, the movement element allows robots to move in response to external changes and adapt to different geographical environments such as flat ground, stairs, ramps, and walls. Last, the thinking element allows robots to consider actions to be taken based on the information obtained from the sensory element. This includes intellectual activities such as judgment, analysis, understanding, and learning. Based on these elements, 
intelligent robots can be classified into sensor robots, interactive robots, and autonomous robots. A sensor robot only uses and processes information obtained from the sensory elements to perform operations controlled by an external operator. An interactive robot has the simple ability to think and judge, and it relies on the dialogue between computer system and human operators for its control and operation. An autonomous robot can engage in correct thinking and judgment and can complete various anthropomorphic tasks without human intervention.

Another technological system relevant to intelligent automation in tourism is the internet-of-things, which is often simply understood as a (digital) network of physical objects, machine-to-machine communications, or things that are wirelessly connected via smart sensors (Atzori, Iera, \& Morabito, 2010; Li, Xu, \& Zhao, 2015). The core concept of the internet-of-things is that "everyday objects can be equipped with identifying, sensing, networking, and processing capabilities that will allow them to communicate with one another and with other devices and services over the internet to achieve some useful objective" (Whitmore, Agarwal, \& Xu, 2015, p. 261). This idea, however, has evolved over time and is continuing to undergo transformations as it is affected by the advent of new concepts and enabling technologies such as cloud computing, big data, and informationcentric networking (Atzori et al., 2017). Atzori et al. (2017) identified three generations of the internet-of-things: (1) tagged objects; (2) things interconnected through web technologies; and (3) social objects, semantic data representation, and cloud of things. Furthermore, the use of AI techniques to add intelligence to interconnected things (i.e., giving everyday objects the ability to comprehend their surroundings and make decisions autonomously) has been considered the next chapter in the internet-of-things, which will lead to the creation of a system called the internet of intelligent things or smart internet-of-things (Arsénio et al., 2014). The consequence of the merging of artificial intelligence, robots, and the internet-of- 
things is pervasive robotics, where robots are present everywhere (in environments with interconnected smart things) and can perform a variety of tasks without human intervention. An example is an automated supermarket run by collaborative robots (cobots) working without human supervision (Özdemir \& Hekim, 2018).

The aforementioned technologies are key elements of intelligent automation in tourism where devices and services are created and deployed in pervasive environments on the way to and within tourism destinations (see Figure 1). As emphasized by Groover (n.d.), automation refers to a system of technologies capable of operating without human intervention performing a process by means of programmed commands combined with automatic feedback control to ensure proper execution of the commands. Applying intelligent automation in tourism can thus be understood as the implementation of an integrated system of next-generation technologies, including artificial intelligence, robotics, and the internet-ofthings, to autonomously operate service tasks within tourism environments without human intervention.

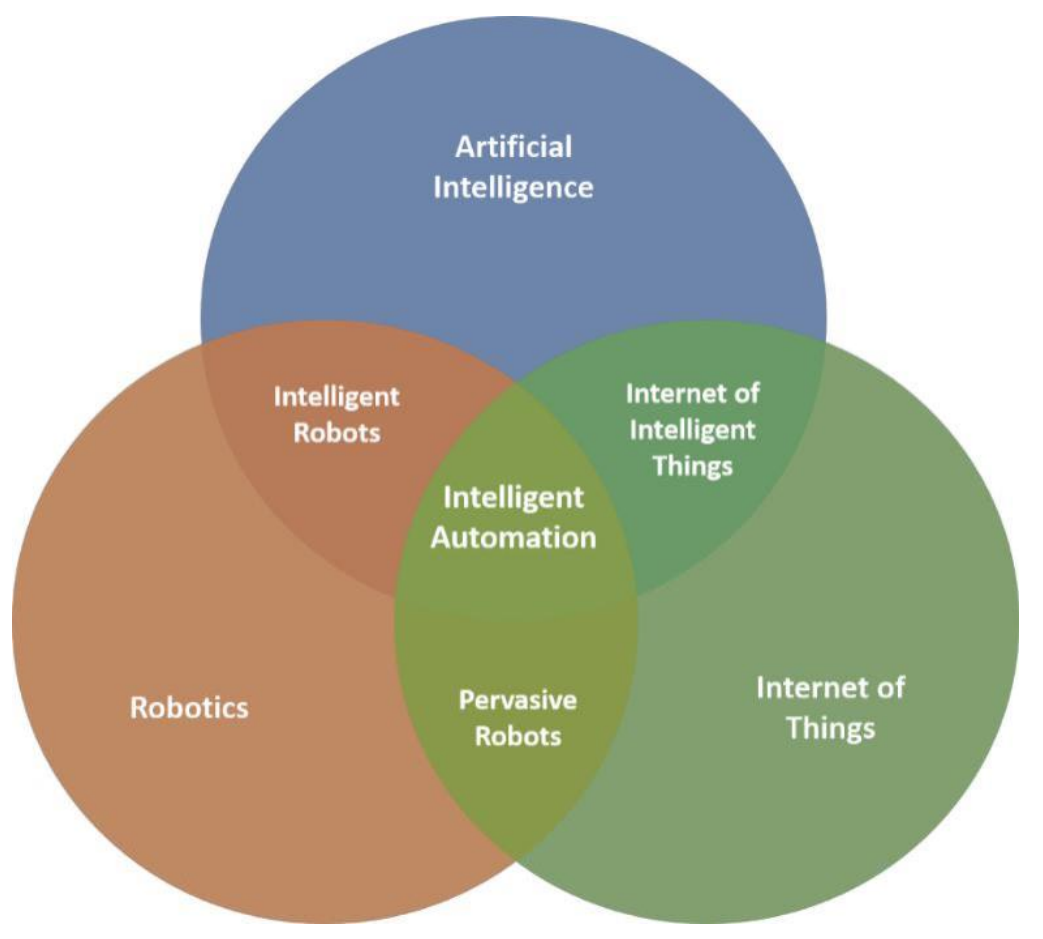

Figure 1. Technological Framework of Intelligent Automation in Tourism 


\section{Applications of Intelligent Automation in Tourism}

The applications of automation in tourism, including benefits and risks for tourists (consumers) and destinations (authorities and service providers), can be mapped into the tourism experience, although some applications are programmed to provide services and assistance throughout the travel journey. Intelligent automation can be applied at the pre-trip stage to provide tourists with travel inspiration and assist them in the processes of information search, booking, and pre-arrival experiences. For service providers, deploying artificial intelligence is critical for omni-channel marketing automation to scale marketing content globally, provide personalized offers and a more straightforward path-to-purchase to customers, and generate and nurture leads. Marketing automation relies on predictive analytics and personalization engines that collect and process relevant customer data, develop customer profiles through identity matching (i.e., based on biographic information; social media profiles, devices, and locations; and so on), and identification of key attributes of customers. With predictive analytics and adaptive modelling, service providers can predict customers' response likelihood and propensity to purchase, leading to prediction of customer lifetime value. This often requires behavioral insights from pattern detection, augmented with such information as credit, risk, and loyalty status. In turn, the use of artificial intelligence techniques allows for faster purchase (booking) rates. Applications such as natural language generation, including text-to-speech combined with automated translation, are used to scale up digital content to a global audience. These systems are then linked to user interfaces that nurture ongoing dialogue, facilitate path-to-purchase, and guide in prearrival experience, such as personal travel assistants (e.g., American Express's Mezi), chatbots, messenger applications with chat service, and provider-specific virtual hosts (e.g., Edwardian Hotel's Edward). At this stage, applications are dominated by 'analytical AI' (cognitive intelligence) tools that collect and process massive amounts of customer data. Some of these interfaces can 
guide tourists throughout their journey, including the post-trip stages of sharing, reminiscing, and follow-up experiences of their travels.

When traveling to and returning from a destination, tourists are faced with challenges around navigation and wayfinding, transport mode choice, and transit experience (e.g., in airports). For service providers and authorities, this is a critical stage for security reasons and requires balancing between travel facilitation and identity verification as tourists cross borders. Airlines have implemented self-service check-in and bag drop. Automated border control system has been pilot tested by airport authorities, airlines, and government agencies in different parts of the world. For example, the US Customs and Border Protection utilizes a system relying on machine learning to flag suspicious people and cargo at border crossings using data such as passenger manifests and information from immigration agencies and Interpol (Melendez, 2018). The iBorderCtrl (Intelligent Portable Control System), an AI border control agent that uses a combination of biometric verification, automated deception detection, document authentication, and risk assessment, was rolled out in Hungary, Latvia, and Greece in 2018. Travelers with a low level of security risk can breeze through security and customs without needing to repeatedly produce proofs of identification, making travel and border crossing a seamless experience. Again, 'analytical AI' tools dominate this area, with intuitive AI starting to gain importance, especially for automated judgment of risk and deception.

This stage also sees the use of 'embodied AI' (integrated with robotics) for mobility and customer service. The last decade has witnessed tremendous progress in self-driving vehicles and autonomous mobility systems, such as people-moving pods and drones. Interactive robots with a classic mobile type, including autonomous trolleys (e.g., KLM's Care-E) and customer service robots (e.g., Munich Airport's Josie Pepper), are deployed to assist travelers at airports. Customer service robots are equipped with real-time question- 
answering and self-learning capabilities; they learn from frequent interactions to continuously refine answers to customer queries. Furthermore, airports are home to retail and hospitality establishments where mechanical and interactive robots are used to serve travelers. Digital travel companions and chatbots on smartphones play an important role in assisting with information for navigation and wayfinding at this stage.

The on-site experience is where various robots, from industrial to android, are adopted to automate service processes in hotels, tourist attractions, and entertainment venues. Intelligent service robots (i.e., interactive robots enhanced with artificial intelligence) are adopted mainly as robot concierges (e.g., Mariott's Mario and Hilton's Connie) designed to deliver on-the-spot answers to questions, to suggest visit-worthy attractions, and to self-learn for improved performance. Intelligent mobile robots, which self-navigate in indoor environments around people and objects, are used to transport items to hotel rooms (e.g., Aloft's Botlr). In-room robot companions (e.g., Henn na Hotel's Tapia) or pervasive agents on headless devices (e.g., Wynn's Amazon Alexa), mostly operating on voice commands, assist hotel guests in controlling room ambience (lighting and temperature), arranging laundry services, making reservations, and so on. So far, front-desk robot receptionists do not have sophisticated interactive capacity. Their presence is mainly an add-on to self-service check-in and check-out systems (e.g., Henn na Hotel's Mirai dinosaur robot).

Stationary industrial robots ('mechanical AI') are implemented in automated locker and storage systems (e.g., Henn na Hotel's cloakroom robot), restaurants (e.g., Henn na Restaurant's robot chef), cafés (e.g., Café X coffee bar system), and bars (e.g., Makr Shakr robotic bartender). For touristic experiences such as sightseeing and tours, robotic tour guides have been adopted in museums and galleries, which mostly use humanoid robots. Multilingual mini humanoid robots equipped with AI, such as Sharp Co.'s RoBoHon, are used to accompany tourists in taxis in Kyoto, Japan, given the increasing interest in 
sightseeing using taxis (Japan Times, 2018). For service providers, the implementation of industrial robots means operational efficiency through speed and endurance as well as consistent outcomes. For example, Café X coffee bar system is capable of producing 120 coffee cups in one hour. Furthermore, the ability to provide on-the-spot customer support through user-friendly human-machine interfaces with humanoid robots allows for enhanced customer experiences, leading to customer satisfaction.

'Disembodied AI' systems used for on-site experiences include digital assistants tied to location-based services that send push notifications and automated real-time translations to facilitate tourist-resident interactions and interpretations of attractions. In fact, digital assistants can guide tourists through post-trip experiences, helping with experience sharing (e.g., writing reviews, collating photographs, and planning for future trips). Supported by distributed ledger technologies such as blockchain, distributed artificial intelligence allows for more efficient analysis of a large volume of text data and training of chatbots to enhance the customer experience. Alongside consumer-facing applications, hotels and other venues are implementing AI systems and the internet-of-things to develop smart, connected buildings, especially for the purposes of energy optimization and facility management (i.e., preventative maintenance and fault detection).

In summary, the applications of intelligent automation in tourism reflect the information-intensive nature of tourism, where tourists' decision-making involves processing a large amount of information. These applications are dominated by the use of 'analytical AI' to automate the process of information retrieval and analysis for marketing and interpretation services. When coupled with customer service purposes, 'analytical AI' is implemented through interactive service robots and/or chatbot. The implementation of 'mechanical AI' (e.g., industrial robots) is still confined to hospitality and transit venues. The integration of artificial intelligence tools and the internet-of-things, together with the collection, 
distribution, and transformation of data in the tourism value chain, provides the necessary infrastructure to support the concept of smart tourism ecosystems (Gretzel, Sigala, Xiang, \& Koo, 2015; Gretzel, Werthner, Koo, \& Lamsfus, 2015). Figure 2 summarizes the aforementioned, illustrating how intelligent automation in tourism can be manifested in tourist-facing devices and interfaces (in blue), powered by various AI capabilities (in grey) to provide solutions to processes, functionalities, activities, and experiences (in green).

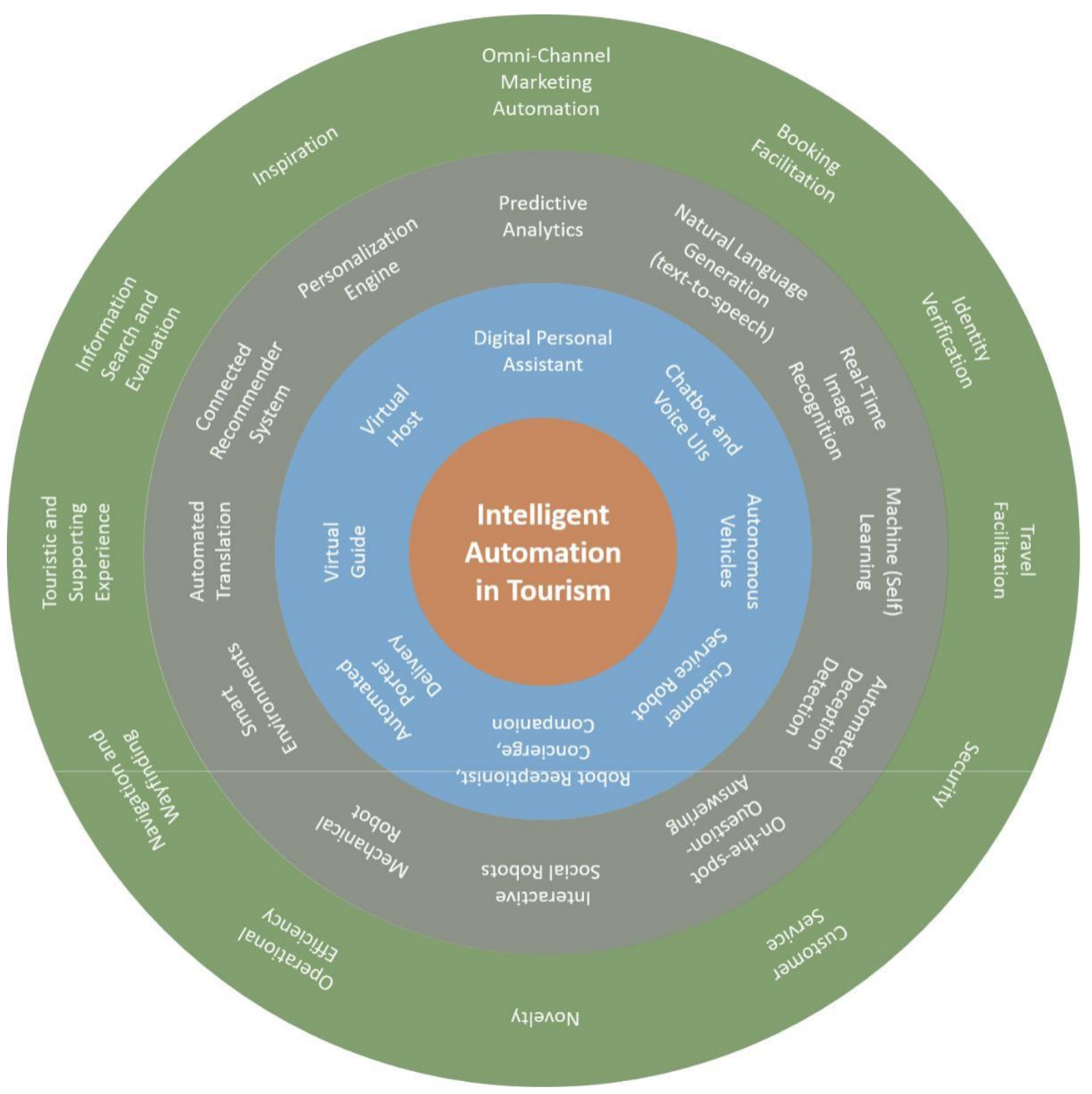

Figure 2. Applications of Automation in Tourism Experiences 


\section{Benefits and Risks of Intelligent Automation}

The applications of intelligent automation imply certain benefits and risks to tourists and destinations. From a service provider's point of view, they can increase productivity, increase efficiency and cost savings, improve support for tourists, make organizational decision-making more efficient, increase safety and security, create flexible workplaces with synergistic cooperation between employees and intelligent systems, and increase job satisfaction - thus increasing the overall well-being of employees (Huang \& Rust, 2018; Kopacek, 2012). 'Mechanical AI' and stationary industrial robots increase productivity through speed and endurance, and customer service robots improve the quality of the customer experience (Kopacek, 2012). However, the dominant application of intelligent automation in tourism thus far is for analytical tasks supporting organizational decisions, leading to efficiency. Regarding efficiency, Huang and Rust (2018) suggested two dominant characteristics of artificial intelligence that are most relevant to services: (1) self-learning, allowing machines to automatically improve with experience; and (2) connectivity, allowing AI's self-learning ability to scale up significantly to the entire network instead of only one machine.

However, the implementation of intelligent automation also comes with risks, including loss of employment; loss of "low-tech" jobs; loss of control due to robot autonomy; and safety, security, and privacy challenges (Boyd \& Holton, 2018; Huang \& Rust, 2018; Jarrahi, 2018; Kopacek, 2012; Nedelkoska \& Quintini, 2018). Mechanical tasks at service jobs are prone to labor replacement by machines (Huang \& Rust, 2018), which in turn causes a shift in skill requirements for employment in the tourism and hospitality industry. Although breakthroughs in artificial intelligence, robotics, and the internet-of-things are expected to create new employment opportunities, 'low-tech' tourism workplaces will gradually disappear, obliterating employment opportunities for local residents. Furthermore, because of 
the dominant implementation of 'analytical AI' tools, not only low-skilled jobs but also specialized jobs are prone to machine replacement. In a report by McKinsey Global Institute (2017), it is estimated that between 400 million to 800 million individuals around the world could be displaced by automation and could need to find jobs by 2030 . Furthermore, it is reported that the risk of being replaced by a robot in the workplace is higher among women than men (Brussevich et al., 2018). Therefore, it has been advised that people need to use their (intrinsically human) talents more fully and to enjoy more leisure (McKinsey Global Institute, 2017). For tourism, an increase in leisure time and the convenience resulting from automating travel facilitation has the potential to drive demand for travel and tourism even higher. This may contribute to problems such as overtourism and an overall increase in pressure on destination ecosystems. Last, AI systems (including the internet of intelligent things) are vulnerable to security and privacy threats; for example, hackers can easily reverse engineer customer data from machine learning models (Gershgorn, 2016). The consequences of a security breach will not only affect tourism and hospitality companies and their customers but also other related industries, residents, and governments.

In an irregular (often unfamiliar) environment that is a tourism destination, when tourists interact mainly with machines in an automated environment, they risk losing human contact and thus social support. This could induce such psychological issues as loneliness and anxiety. Other risks are associated with constant collection of sensitive personal data, including biometric and behavior data, resulting in issues of privacy, in terms of both identifiability and surveillance, and security. Additionally, tourists may not be aware of the range of privacy and security threats associated with automated systems powered by artificial intelligence technologies (Tussyadiah, Li, \& Miller, 2019), making them prone to making uninformed privacy decisions. 
The rapid development of artificial intelligence and its related technologies should be balanced with strategies and policies that endeavor to optimize the benefits and minimize the risks of intelligent automation in tourism. These might include training the current workforce in new skills, implementing educational reform, creating new safety and security standards for intelligent automation, informing tourists about privacy issues, and creating standards for transparent and responsible use of customer data. To arrive at these solutions, it is vital to develop comprehensive knowledge of issues around implementation of intelligent automation in tourism, including the range of impacts of this implementation. Research is thus needed to prepare the sector for a more automated future and, at the same time, thwart technological anxiety and unreasonable fear mongering that would stifle progress in research and development of artificial intelligence and its related technologies (Gurkaynak et al., 2016; McKinsey Global Institute, 2017).

\section{A Research Agenda}

Based on the roles of intelligent automation in tourism and the potential benefits and risks of its related applications, priority should be given to research in the following areas: designing beneficial artificial intelligence, facilitating adoption, assessing impacts of automation, and creating a sustainable future with intelligent systems (see Table 1). Adoption of advanced technologies will be beneficial for the industry and society, but further research is needed to ascertain the requirements for robust artificially intelligent technological systems (herein called AI systems) and to apply them properly. This goes hand in hand with the assessment of impacts to ensure that the implementation of intelligent automation supports the attainment of sustainable development goals through tourism. 
Table 1. Automating Tourism: A Research Agenda

\begin{tabular}{|c|c|c|}
\hline Priorities & Research Questions & $\begin{array}{l}\text { Conceptual and Methodological } \\
\text { Approaches }\end{array}$ \\
\hline $\begin{array}{l}\text { Designing } \\
\text { Beneficial } \\
\text { Artificial } \\
\text { Intelligence }\end{array}$ & $\begin{array}{l}\text { - How can we use artificial intelligence } \\
\text { techniques to create value for tourism? } \\
\text { - Which aspects of tourism experience can } \\
\text { be enhanced with the application of } \\
\text { intelligent automation? } \\
\text { - On a scale from manual to full } \\
\text { automation, where is the optimum } \\
\text { implementation of artificial intelligence, } \\
\text { considering the domain-specificity of } \\
\text { tourism? } \\
\text { - How can we implement artificial } \\
\text { intelligence techniques to influence } \\
\text { tourist experience in user-facing } \\
\text { services? } \\
\text { - Which desired user behaviors do we } \\
\text { want AI systems to facilitate/bring about } \\
\text { in tourists, residents, and other tourism } \\
\text { stakeholders? } \\
\text { - What are the persistent behavioral } \\
\text { problems of tourism stakeholders that } \\
\text { artificial intelligence techniques can help } \\
\text { address or change? } \\
\text { - What are the design requirements for AI } \\
\text { - Howstems to target the aforementioned } \\
\text { issues? How can AI systems be robust } \\
\text { against these requirements? } \\
\text { privacy violation? } \\
\text { we retain some forms of meane AI systems secure? } \\
\text { human control in light of the autonomy } \\
\text { of these systems? }\end{array}$ & $\begin{array}{l}\text { - Design thinking and design research } \\
\text { methods (Lindvall, Molin, \& Löwgren, } \\
\text { 2018; Tussyadiah, 2014) applied to } \\
\text { human-computer interaction, such as } \\
\text { LEGO® Serious Play® method (Tuomi, } \\
\text { Tussyadiah, \& Stienmetz, 2019), } \\
\text { cybernetic thinking (Martelaro \& Ju, } \\
\text { 2018), speculation technique (Wong, } \\
\text { 2018), and prototyping of autonomous } \\
\text { systems (van Allen, 2018) } \\
\text { - User experience design (Lindvall, Molin, } \\
\text { \& Löwgren, 2018; Martelaro \& Ju, 2018); } \\
\text { technological mediation (Tussyadiah, } \\
\text { 2014; Tussyadiah \& Fesenmaier, 2009) } \\
\text { - Computers as persuasive technology } \\
\text { (Captology; Fogg, 2009); Nudge theory } \\
\text { (Thaler \& Sunstein, 2008), including } \\
\text { digital nudging (Schneider, Weinmann, \& } \\
\text { vom Brocke, 2018) (see, e.g., Tussyadiah, } \\
\text { Li, \& Miller [2019] and Tussyadiah \& } \\
\text { Miller [2019] for application in tourism) } \\
\text { • Verification and validation of artificial } \\
\text { intelligence (Menzies \& Pecheur, 2005; } \\
\text { Russell, Dewey, \& Tegmark, 2015) } \\
\text { - Anonymization and de-identification of } \\
\text { personal data (Garfinkel, 2015; Khalil \& } \\
\text { Ebner, 2016) } \\
\text { (Duman-in-the-loop or human-on-the-loop } \\
\text { (Dautenhahn, 2011; Schirner et al., 2013) }\end{array}$ \\
\hline $\begin{array}{l}\text { Facilitating } \\
\text { Adoption }\end{array}$ & $\begin{array}{l}\text { - What is the adoption rate of intelligent } \\
\text { automation in the sector and what is the } \\
\text { future trend? } \\
\text { - What are the determinants of and } \\
\text { impediments to adoption AI systems and } \\
\text { devices by tourists, employees, } \\
\text { residents, etc.? } \\
\text { - What are the drivers and barriers of } \\
\text { organizational adoption of intelligent } \\
\text { automation in the tourism sector? } \\
\text { - How can we facilitate responsible } \\
\text { adoption of intelligent automation in the } \\
\text { tourism sector? } \\
\text { - How can we increase trust in artificial } \\
\text { intelligence and intelligent systems? } \\
\text { intelligence and increase its technical } \\
\text { transparency? }\end{array}$ & $\begin{array}{l}\text { - Diffusion of Innovation Theory (Roger, } \\
\text { 2003); Theory of Reasoned Action } \\
\text { (Fishbein \& Ajzen, 1975); Theory of } \\
\text { Planned Behavior (Ajzen, 1991); } \\
\text { Technology Acceptance Model (Davis, } \\
\text { 1989) and its extension; Unified Theory of } \\
\text { Acceptance and Use of Technology } \\
\text { (UTAUT) and UTAUT2 (Venkatesh et al., } \\
\text { 2003; Venkatesh, Thong, \& Xu, 2012) } \\
\text { - Organizational adoption of innovation } \\
\text { (Frambach, 1993; Frambach \& } \\
\text { Shillewaert, 2002; MacVaugh \& } \\
\text { Schiavone, 2010) } \\
\text { - Transformational leadership (Bass, 1990) } \\
\text { - Negative Attitude towards Robots } \\
\text { (Nomura, Kanda, \& Suzuki, 2006; } \\
\text { Nomura et al., 2006), Technophobia } \\
\text { (Brosnan, 1998); Uncanny Valley Theory } \\
\text { (Mori, 2012) } \\
\text {-Explainable AI' (Doran, Schulz, \& } \\
\text { Besold, 2017; Monroe, 2018) }\end{array}$ \\
\hline
\end{tabular}




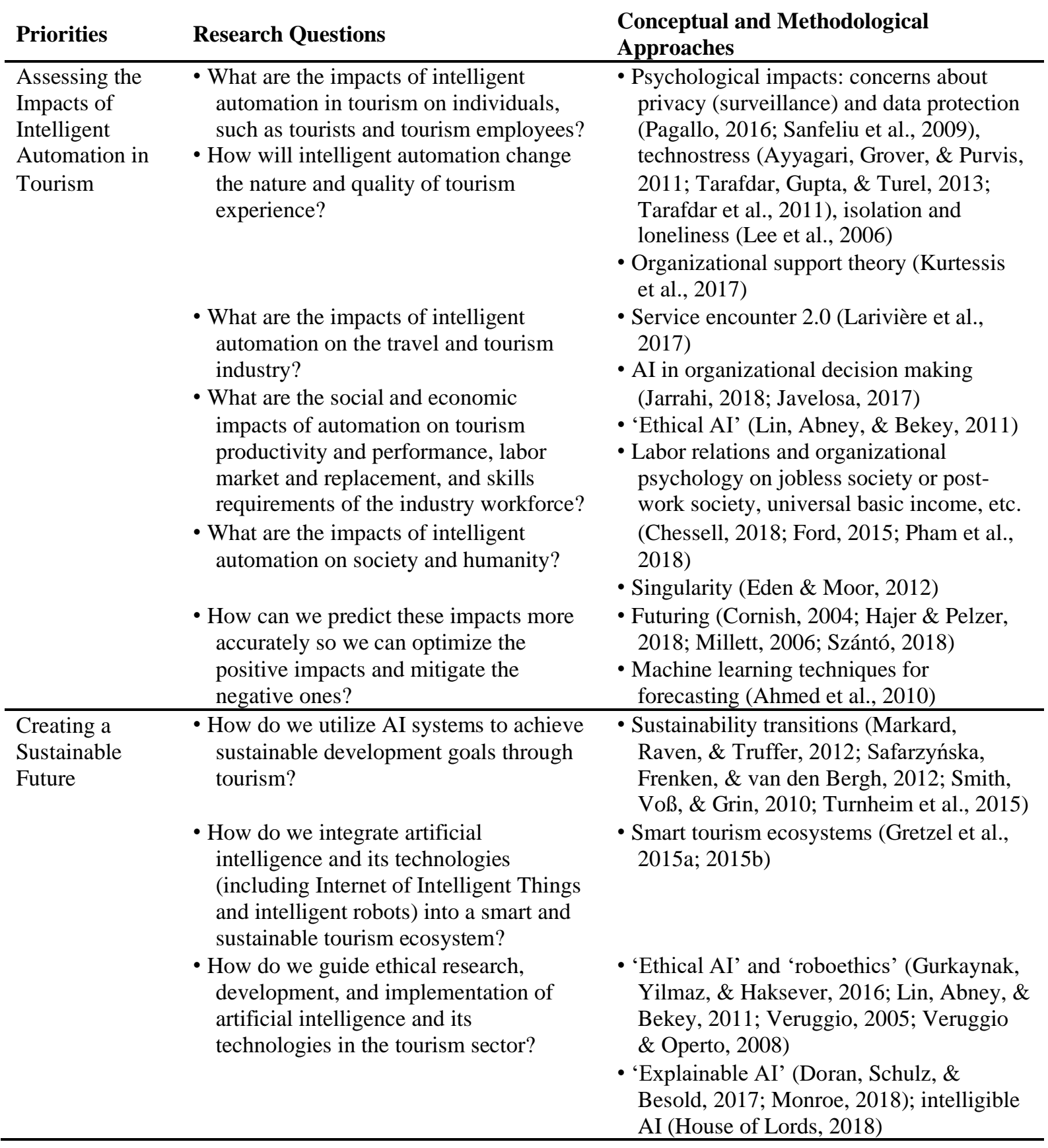

\section{Designing Beneficial Artificial Intelligence}

The key to implementing intelligent automation is defining, conceptualizing, designing, and delivering AI systems that are beneficial to the travel and tourism industry. Research needs to focus on knowing what we want the systems to do and ensuring that they perform as desired. Research effort should be spent on (1) identifying moments in or aspects of tourism experiences to enhance by implementing intelligent automation, (2) creating design 
requirements for beneficial AI systems, and (3) developing systems that are robust against these requirements.

To explore the desired behavior of these systems, it is important to identify how intelligent automation can enhance the various aspects of the tourism experience and the moments along the tourist's journey. This is where approaches to experience design, which is multidisciplinary in nature (e.g., design studies, psychology, anthropology, behavioral science, business studies, human-computer interaction), and design research methods, such as cybernetic thinking (Martelaro \& Ju, 2018), LEGO® Serious Play® (Tuomi, Tussyadiah, \& Stienmetz, 2019), speculation technique (Wong, 2018), and prototyping (van Allen, 2018), can be useful (Churchill, van Allen, \& Kuniavsky, 2018). Designing tourism experiences requires an orchestration of various elements, developed based on in-depth understanding of tourist requirements, to ensure not only seamless but also memorable tourism experiences (Tussyadiah, 2014). The design of tourism experiences is expressed through a concept covering the entire journey from pre-trip to post-trip, paying particular attention to facilitating engagement and participation. The roles of artificial intelligence technologies should be explicated in terms of how systems can facilitate/mediate, augment, and/or substitute tourists' interactions (i.e., user experience; Lindvall, Molin, \& Löwgren, 2018). A range of desired behaviors for systems targeting specific issues along tourism touch points will be helpful in building requirements for beneficial AI systems.

Designing beneficial artificial intelligence is also concerned with providing technological solutions to persistent design problems. To this end, perspectives from psychology, cognitive and behavioral sciences, and information systems will shed light on the persistent behavioral problems exhibited by tourists, such as lack of discipline, lack of attention, or lack of cognitive abilities. Requirements for AI systems should address these issues by, for instance, discouraging tourists from making uninformed decisions that result in 
suboptimal experiences. Nudge theory (Thaler \& Sunstein, 2008), including digital nudging (Schneider, Weinmann, \& vom Brocke, 2018), can be applied for this purpose (Tussyadiah et al., 2019, Tussyadiah \& Miller, 2019, for examples from the tourism industry). AI systems can be deployed to tackle acute destination problems demanding effective realtime management of tourist flow (e.g., by sending push notifications and recommending alternative destinations). Research can use the lens of Captology (computers as persuasive technologies; Fogg, 2009), technological mediation (Tussyadiah, 2017; Tussyadiah \& Fesenmaier, 2009), and human-computer interaction (Tung \& Law, 2017).

Next, it is important to capture how tourism experiences change as a result of intelligent automation. Because of the interdependence between environmental dimensions of destination, implementation of AI systems may change the social (and physical) organization of tourism destinations. For example, a combination of predictive analytics and virtual tourism content may be able to sway tourists into visiting less popular attractions in a destination in an attempt to redistribute activities and impacts. This will transform the tourists' experience and create new touristic places in the destinations. Therefore, research exploring new tourism experiences due to intelligent automation will be necessary to arrive at the conceptualization of the "automated tourism experience." The concept can then inform design requirements for these systems as an integral part, dominant or otherwise, of the tourism experience.

From a technical perspective, designing beneficial artificial intelligence requires emphasizing the importance of robust artificial intelligence (Russell, Dewey, \& Tegmark, 2015). This includes robustness against requirements, exploitation, bugs, and threats of cyberattacks. Russell et al. (2015) highlight the importance of verification (designing the system right) and validation (designing the right system) (also see Menzies \& Pecheur, 2005). First, AI systems necessitate access to a large amount of data; in tourism, these data are 
largely tourists' personal data. They should be designed to make maximum use of data with minimum possible infringement on the privacy of individuals (House of Lords, 2018; Tussyadiah et al., 2019). Research can focus on addressing this issue through approaches to anonymization and de-identification of data (Garfinkel, 2015; Khalil \& Ebner, 2016). Second, there is a need for designing intelligible artificial intelligence (House of Lords, 2018), making AI understandable and explainable to developers, users, and regulators (Monroe, 2018). Increasing the technical transparency of artificial intelligence and reducing bias should be another focus of research. Third, to address security issues, designing artificial intelligence requires standards to guide behaviors in safety-critical situations, to detect intrusion and potential exploitation, and to prevent harmful events (Russell et al., 2015). Last, research should be conducted on how to retain some form of meaningful human control in light of the autonomy of these systems. This includes implementation of ideas around human in the loop or human on the loop (Dautenhahn, 2011; Schirner et al., 2013).

\section{Facilitating Adoption}

The next challenge is to facilitate the adoption of (beneficial) intelligent automation by tourism organizations, employees, and tourists. Research needs to identify the current adoption rate and future trends, as well as the relevant drivers and barriers to adoption. Theories and models behind adoption of technological innovation, such as those assessing innovation diffusion, acceptance, resistance, use, and (dis-)continuance of use will be beneficial in this area. These include diffusion of innovation theory (Roger, 2003), theory of reasoned action (Fishbein \& Ajzen, 1975), and theory of planned behavior (Ajzen, 1991); the technology adoption model (TAM; Davis, 1989) and the extended TAM2 model (Venkatesh \& Davis, 2000); the Unified Theory of Acceptance and Use of Technology (UTAUT) and UTAUT2 (Venkatesh et al., 2003; Venkatesh, Thong, \& Xu, 2012). 
At an individual level, in addition to the determinants and impediments to the adoption of general technology, such as ease of use, usefulness, and technology self-efficacy, research efforts should be spent on identifying factors unique to artificial intelligence, robotics, and the internet-of-things that influence adoption or rejection of innovation, including dimensions of trust and risks. For example, researchers have suggested a certain level of anxiety in society when it comes to interacting with robots, leading to a negative attitude toward robots (Nomura, Kanda, \& Suzuki, 2006; Nomura et al., 2006). This attitude may be amplified by negative sentiments about AI and robotics in news media. Theories underlying technophobia (Brosnan, 1998) and the uncanny valley theory (Mori, 2012) should be consulted to better understand consumers' and employees' attitude toward intelligent machines in tourism service settings (Murphy et al., 2019). Management theories such as organizational support theory (Kurtessis et al., 2017) will assist in obtaining employees' support for the adoption of intelligent automation in the workplace. Attempts have been made to measure the attitude and intention to adopt intelligent machines by consumers $(\mathrm{Lu}, \mathrm{Cai} \&$ Gursoy, 2019; Tussyadiah \& Park, 2018) and employees (Li, Bonn, \& Ye, 2019) in hospitality.

Identifying factors influencing the adoption of innovation at an organizational level is important to facilitate and accelerate the application of intelligent automation in tourism. Similarly, understanding the limits to the diffusion of innovation in organizations will also help understand the barriers to adoption by the sector. The management literature offers information on concepts underlying organizational adoption and diffusion of innovation (Frambach, 1993; Frambach \& Shillewaert, 2002; MacVaugh \& Schiavone, 2010) and transformational leadership (Bass, 1990), a factor proven in the literature to accelerate technological innovation in organizations. Research should explicate how intelligent automation fits the strategic emphasis of tourism organizations, private and public, as well as 
the competitive environments within the sectors. Endeavors to remove barriers and encourage responsible adoption can then be suggested, including government initiatives to incentivize adoption (campaigns, grants) and/or organizational efforts to educate potential users.

\section{Assessing the Impacts of Intelligent Automation on Tourism}

To optimize the benefits of intelligent automation in tourism, it is critical to anticipate the range of positive and negative impacts of automation on individuals (tourists, employees), the industry, and society. Gretzel (2011) conducted a review of the roles and impacts of intelligent system in tourism, although the researcher did not focus solely on artificial intelligence. Further, Lin, Abney, and Bekey (2011) suggested three areas of ethical problems arising from the implementation of robots: safety and errors, law and ethics, and social impacts. An important aspect in the adoption of intelligent machines is anticipating service failure as a result of technological (programming) errors during human-robot interaction. Research thus needs to address how to minimize risk of harm from artificially intelligent agents in various service interaction situations. For users, psychological impacts of humanrobot interaction, such as issues of privacy (surveillance) and data protection (Pagallo, 2016; Sanfeliu et al., 2009), emotional responses to the closeness of robot appearance to that of humans (Mori, 2012; Walters et al., 2008), technostress (Ayyagari, Grover, \& Purvis, 2011; Tarafdar, Gupta, \& Turel, 2013; Tarafdar et al., 2011), and isolation (loneliness) due to reduced interpersonal interaction and increased solitary activities (Lee et al., 2006), are worthy of investigation. Assessing how these issues will further affect the structure and quality of tourism experiences is also essential.

Another important research area is the transformation intelligent automation will bring to organizations, including the changes to organizational decision-making process as artificial intelligence replaces portfolio managers (Javelosa, 2017) and the unintended 
consequences of AI (-assisted) decisions (Jarrahi, 2018). Research should explore the complementarity of humans and intelligent systems in collaborative decision-making and task allocations. Further, investigating the changing roles of employees and customers in automated services and the effect of working alongside intelligent systems on role performance is vital to (re)conceptualize the automated tourism and hospitality service experience's production and consumption in light of intelligent automation (see Larivière et al., 2017).

The socioeconomic impacts of intelligent automation on the tourism industry and local residents, as well as the economy on a broader level, have to do with changes in productivity, with when and to what extent tourism and hospitality service jobs are going to be replaced by intelligent machines, and with the consequences for wages, income distribution (inequality), gender issues, and overall wealth in tourism destinations. In regard to labor, automation also increases concerns of loss of skills and knowledge in society due to (over)dependence on technology (Lin et al., 2011) as well as the potential of a jobless society in the future (Chessell, 2018; Pham et al., 2018). Further impacts of the development of intelligent machines have been debated in the context of technological singularity, a phenomenon where technological growth becomes uncontrollable and irreversible and artificial intelligence becomes smarter than humans, leading to the end of human civilization (Eden \& Moor, 2012).

Assessing these impacts necessitates new ways of measuring performance of the tourism sector as automation is applied to it. Research should be devoted to finding accurate measures of productivity that capture the full benefit of automation, and to labor market forecasting, in order to optimize the economic impacts of automation dominated by artificial intelligence (Brynjolfsson, Rock, \& Syverson, 2018; Russel et al., 2015). The same goes for assessing social impacts, specifically with regard to guest-host relations and residents' 
support for tourism development. In addition to using machine learning techniques to improve accuracy of prediction and forecasting (Ahmed et al., 2010), techniques such as futuring (i.e., envisioning the futures) and future making (Cornish, 2004; Hajer \& Pelzer, 2018; Millett, 2006; Szántó, 2018) should be applied to identify desired futures and ways to get there.

\section{Creating a Sustainable Future}

Eventually, research endeavors should be devoted to determining how intelligent automation can help futureproof the tourism sector. The next step after obtaining knowledge of the range of benefits and problems resulting from implementation of intelligent automation is recognizing the range of approaches for mitigating negative impacts and optimizing the benefits of automation in tourism. The concept of sustainability transition (Markard, Raven, \& Truffer, 2012; Safarzyńska, Frenken, \& van den Bergh, 2012; Smith, Voß, \& Grin, 2010; Turnheim et al., 2015) is critical to guide research in this area, and specifically to identify how AI systems can be leveraged to shape transition pathways to sustainable development through tourism. Government policy is fundamental in managing potential adverse effects of intelligent automation in the industry and in society. Examples include policy interventions through education and training programs to address gaps in the skills required for AI-related jobs or to prevent loss of skills due to dependence on automation, incentives to support labor-intensive sectors such as hospitality, and a universal basic income to address potential mass unemployment due to automation. Additionally, tourism organizations and other stakeholders can apply different intervention strategies to promote responsible use behaviors among tourists and employees.

In the foreseeable future, intelligent automation will start to dominate tourism and, as a consequence, reduce the need for personal, face-to-face interactions between tourists and 
residents (tourism employees) even more than it is doing today. Lack of socialization may lead to erosion of common values essential for an organized social life, such as concern for the welfare of others and for environmental conservation. The challenge is to assess the extent to which artificial intelligence and robots can be part of the solution for these nascent issues. As people increasingly use and rely on virtual assistants and robots to navigate their daily life and travel needs, it is necessary to fundamentally shift our perception about the role of intelligent agents in society from that of mere tools to large and complex social actors. Computational systems can be designed to guide, inform, and mentor humans by raising awareness of biophysical limits and human well-being and encouraging responsible and resource-efficient behavior. The key to effective human-robot cooperation to support a sustainable society lies with and around humans. Therefore, research is needed to address how we can humanize humans in the era of intelligent machines and contribute to the development of roboethics (Kopacek, 2012; Lin et al., 2011; Veruggio, 2005; Veruggio \& Operto, 2008). That is, research should focus on creating scientific, cultural, and technical tools to promote and encourage the latest trends for the advancement of society and individuals and to help prevent overuse, misuse, disuse, and abuse of artificial intelligence and robots (Kopacek, 2012). The principles of roboethics should then be considered in designing requirements for robust artificial intelligence, creating a feedback loop to designing beneficial AI (the first research priority).

\section{Concluding Remarks}

As intelligent automation has started to enter the realm of tourism experiences, it is important to anticipate and shape the automated future of travel and tourism. Research on intelligent automation, including automation applied to the services sectors, has been dominated by the technical aspect of intelligent systems, namely how to construct smarter, more useful 
artificial intelligence for service delivery (Nieto et al., 2014; Pinillos et al., 2016; Yu et al., 2012; Zalama et al., 2014). This is mostly due to the virtuous cycle of research and development of artificial intelligence. Artificial intelligence is expected to have significant positive impacts on the economy because of its dynamic efficiency, and it is rapidly becoming one of the priority areas in the industrial strategies of most developed nations in the world (Dutton, 2018; Rao, 2017). Consequently, research funds are being allocated to projects that would give these nations momentum in the race to find the next significant breakthrough in the development of AI and intelligent machines (Russell et al., 2015). The faster artificial intelligence technology advances, the more will be the resources available to invest in technical research.

Research on the social science aspects of intelligent automation, which are needed in light of the implications of intelligent automation for the processes underlying social interactions and governing society, is lagging behind. Most studies have concentrated on the ethical (and legal) aspects of artificial intelligence and its implementation (Gurkaynak et al., 2016; Kopacek, 2012; Veruggio, 2010; Veruggio \& Operto, 2008) and its potential implications for social transformation of work and skills (Huang \& Rust, 2018; Jarrahi, 2018), as well as the early adoption of intelligent automation in services (Colby et al., 2016). Research needs to prioritize the social science aspects of intelligent automation as much as the technical aspects (Russell et al., 2015).

This paper provides an overarching research agenda to systematically build knowledge in this area from the social science perspectives and to pursue rigorous scientific research that will guide policy interventions and efforts from various stakeholders, such as governments and tourism organizations, to ensure the responsible adoption of intelligent automation in tourism. By asking key research questions around artificial intelligence, its related technologies, and their applications in tourism, this paper suggests four research 
priorities: designing beneficial artificial intelligence, facilitating adoption, assessing impacts of intelligent automation, and creating a sustainable future with AI systems. Contributions to theorizing and shaping the future of tourism in the era of artificial intelligence using multiple disciplinary perspectives and methodologies are expected to enrich industry- and policyrelevant knowledge production in this area.

\section{References}

Addo, E., Yagci, K. (2014) Automation, tourism. In: Jafari J., Xiao H. (eds). Encyclopedia of Tourism. Springer, Cham.

Ahmed, N.K., Atiya, A.F., Gayar, N.E., El-Shishiny, H. (2010). An Empirical Comparison of Machine Learning Models for Time Series Forecasting. Econometric Reviews, 29(5-6), $594-621$.

Ajzen, I. (1991). The theory of planned behavior. Organizational Behavior and Human Decision Processes, 50(2), 179-211.

Arsénio, A., Serra, H., Francisco, R., Nabais, F., Andrade, J., Serrano, E. (2014). Internet of Intelligent Things: Bringing artificial intelligence into things and communication networks. In: Xhafa F., Bessis N. (eds.), Inter-Cooperative Collective Intelligence: Techniques and Applications. Studies in Computational Intelligence. Springer, Berlin.

Atzori, L., Iera, A., Morabito, G. (2010). The Internet of Things: A survey. Computer Networks, 54, 2787-2805.

Atzori, L., Iera, A., Morabito, G. (2017). Understanding the Internet of Things: Definition, potentials, and societal role of a fast evolving paradigm. Ad Hoc Networks, 56, 122-140.

Ayyagari, R., Grover, V., Purvis, R. (2011). Technostress: Technological Antecedents and Implications. MIS Quarterly, 35(4), 831-858. 
Bass, B.M. (1990). From transactional to transformational leadership: Learning to share the vision. Organizational Dynamics, 18(3), 19-31.

Bimonte, S., Punzo, L.F. (2016). Tourist development and host-guest interaction: An economic exchange theory. Annals of Tourism Research, 58, 128-139.

Boyd, R., Holton, R.J. (2018). Technology, innovation, employment and power: Does robotics and artificial intelligence really mean social transformation? Journal of Sociology, 54(3), 331-345.

Brosnan, M.J. (1998). Technophobia: The Psychological Impact of Information Technology. Routledge, London.

Brussevich, M., Dabla-Norris, E., Kamunge, C., Karnane, P., Khalid, S., Kochhar, K. (2018). Gender, technology, and the future of work. International Monetary Fund (IMF) Staff Discussion Notes.

https://www.imf.org/ /media/Files/Publications/SDN/2018/SDN1807.ashx

Brynjolfsson, E., Rock, D., Syverson, C. (2018). Artificial intelligence and the modern productivity paradox: a clash of expectations and statistics. National Bureau of Economic Research, Inc.

Chessell, D. (2018). The jobless economy in a post-work society: How automation will transform the labor market. Psychosociological Issues in Human Resource Management $6(2), 74-79$.

Churchill, E., van Allen, P., Kurniavsky, M. (2018). Special Topic: Designing AIIntroducton. Interactions, 25(6), 34-37.

CNN (2018). KLM'S new airport robot Care-E will guide you to the gate. https://edition.cnn.com/travel/article/klm-airport-robot/index.html 
Colby, C.L., Mithas, S., Parasuraman, A. (2016). Service Robotics: How ready are consumers to adopt and what drives acceptance? Proceedings of Frontiers in Service Conference, June 23-26, 2016, Bergen, Norway.

Cornish, E. (2004). Futuring: The Exploration of the Future. World Future Society, Bethesda.

Dautenhahn, K. (2011). The art of designing socially intelligent agents: Science, fiction, and the human in the loop. Applied Artificial Intelligence, 12(7-8), 573-617.

Davis, F.A. (1989). Perceived usefulness perceived ease of use and user acceptance of information technology. MIS Quarterly, 8, 318-339.

Doran, D., Schulz, S., Besold, T.R. (2017). What does explainable AI really mean? A new conceptualization of perspectives. https://arxiv.org/abs/1710.00794

Dutton, T. (2018). An overview of national AI strategies. https://medium.com/politics-ai/anoverview-of-national-ai-strategies-2a70ec6edfd

Eden, A.H., Moor, J.H. (2012). Singularity hypotheses: A Scientific and Philosophical Assessment. Springer, Dordrecht.

Encyclopedia Britannica (n.d.). Artificial Intelligence. https://www.britannica.com/technology/artificial-intelligence

Fishbein, M., Ajzen, I. (1975). Belief, Attitude, Intention, and Behavior: An Introduction to Theory and Research. Addison-Wesley, Reading.

Fogg, B.J. (2009). A behavior model for persuasive design. Proceedings of the 4th International Conference on Persuasive Technology. ACM, New York.

Ford, M. (2015). The Rise of the Robots: Technology and the Threat of Mass Unemployment. Basic Books, New York.

Frambach, R.T. (1993). An integrated model of organizational adoption and diffusion of innovations. European Journal of Marketing, 27(5), 22-41. 
Frambach, R.T., Schillewaert, N. (2002). Organizational innovation adoption: A multilevel framework of determinants and opportunities for future research. Journal of Business Research, 55(2), 163-176.

Garfinkel. S.L. (2015). De-Identification of Personal Information. National Institute of Standards and Technology. http://dx.doi.org/10.6028/NIST.IR.8053

Gershgorn, D. (2016). Stealing an AI algorithm and its underlying data is a "high-school level exercise." https://qz.com/786219/stealing-an-ai-algorithm-and-its-underlying-datais-a-high-school-level-exercise/

Gretzel, U. (2011). Intelligent systems in tourism: A social science perspective. Annals of Tourism Research, 38(3), 757-779.

Gretzel, U., Sigala, M., Xiang, Z., Koo, C. (2015). Smart tourism: foundations and developments. Electronic Markets, 25(3), 179-188.

Gretzel, U., Werthner, H., Koo, C., Lamsfus, C. (2015). Conceptual foundations for understanding smart tourism ecosystems. Computers in Human Behavior, 50, 558-563.

Groover, M. (n.d.). Automation. https://www.britannica.com/technology/automation Guardian, the (2015). Inside Japan's first robot-staffed hotel. https://www.theguardian.com/travel/2015/aug/14/japan-henn-na-hotel-staffed-by-robots

Gurkaynak, G., Yilmaz, I., Haksever, G. (2016). Stifling artificial intelligence: Human perils. Computer Law \& Security Review, 32(5), 749-758.

Hajer, M.A., Pelzer, P. (2018). 2050-An Energetic Odyssey: Understanding “Techniques of Futuring" in the transition towards renewable energy. Energy Research \& Social Science, 44, 222-231.

House of Lords (2018). AI in the UK: ready, willing and able? https://publications.parliament.uk/pa/ld201719/ldselect/ldai/100/100.pdf 
Huang, M.H., Rust, R.T. (2018). Artificial intelligence in service. Journal of Service Research, 21(2), 155-172.

International Federation of Robotics (2018). Artificial Intelligence and Robotics. https://ifr.org/downloads/papers/Media_Backgrounder_on_Artificial_Intelligence_in_Ro botics_May_2018.pdf

International Organization for Standardization (2012). ISO/CD 8373. Robots and robotic devices-Vocabulary. https://www.iso.org/standard/75539.html

Ivanov S., Webster C. (2019a). Perceived Appropriateness and Intention to Use Service Robots in Tourism. In: Pesonen J., Neidhardt J. (eds) Information and Communication Technologies in Tourism 2019. Springer, Cham

Ivanov S., Webster C. (2019b). What Should Robots Do? A Comparative Analysis of Industry Professionals, Educators and Tourists. In: Pesonen J., Neidhardt J. (eds) Information and Communication Technologies in Tourism 2019. Springer, Cham

Ivanov, S., Webster, C. (2019c). Robots in tourism: A research agenda for tourism economics. Tourism Economics, 1-21.

Japan Times, the (2018). Sharp's humanoid RoBoHon robot to guide tourists in Kyoto. https://www.japantimes.co.jp/news/2018/09/11/business/sharps-humanoid-robohonrobot-guide-tourists-kyoto/\#.XAHf_y10cnU

Jarrahi, M.H. (2018). Artificial intelligence and the future of work: Human-AI symbiosis in organizational decision making. Business Horizons, 61(4), 577-586.

Javelosa, J. (2017). Major firm announces it's replacing its employees with A.I. Welcome to the age of automation. https://futurism.com/major-firm-announces-its-replacing-itsemployees-with-a-i

Khalil, M., Ebner, M. (2016). De-Identification in Learning Analytics. Journal of Learning Analytics, 3(1), 129-138. 
KLM (2015). Robot "Spencer" to guide KLM passengers at Amsterdam Airport

Schiphol. https://news.klm.com/robot-spencer-to-guide-klm-passengers-atamsterdam-airport-schiphol/

KLM (2016). Spencer robot completed tests guiding KLM passengers at Schiphol. https://news.klm.com/spencer-robot-completed-tests-guiding-klm-passengers-at-schiphol/ Kopacek, K. (2012). Roboethics. IFAC Proceedings Volumes, 45(10), 67-72.

Kurtessis, J.N., Eisenberger, R., Ford, M.T., Buffardi, L.C., Stewart, K.A., Adis, C.S. (2017). Perceived organizational support: A meta-analytic evaluation of organizational support theory. Journal of Management, 43(6), 1854-1884.

Lai, R., Lin, W., Wu, Y. (2018). Review of research on the key technologies, application fields and development trends of intelligent robots. In: Chen, Z., Mendes, A., Yan, Y., Chen, S. (eds) Intelligent Robotics and Applications. ICIRA 2018. Springer, Cham

Larivière, B., Bowen, D., Andreassen, T.W., Kunz, W., Sirianni, N.J., Voss, C., Wünderlich, N.V., De Keyser, A. (2017). "Service Encounter 2.0”: An investigation into the roles of technology, employees and customers. Journal of Business Research, 79, 238-246.

Lee, K.M., Jung, Y., Kim, J., Kim, S.R. (2006). Are physically embodied social agents better than disembodied social agents?: The effects of physical embodiment, tactile interaction, and people's loneliness in human-robot interaction. International Journal of Human-Computer Studies, 64(10), 962-973.

Li, J., Bonn, M.A., Ye, H. (2019). Hotel employee's artificial intelligence and robotics awareness and its impact on turnover intention: The moderating roles of perceived organizational support and competitive psychological climate. Tourism Management, $72,172-181$.

Li, S., Xu, D.L., Zhao, S. (2015). The internet of things: A survey. Information Systems Frontiers, 17, 243-259. 
Lin, P., Abney, K., Bekey, G. (2011). Robot ethics: Mapping the issues for a mechanized world. Artificial Intelligence, 175, 942-949.

Lin, Z., Chen, Y., Filieri, R. (2017). Resident-tourist value co-creation: The role of residents' perceived tourism impacts and life satisfaction. Tourism Management, 61, 436-442.

Lindvall, M., Molin, J., Löwgren, J. (2018). From machine learning to machine teaching: The importance of UX. Interactions, 25(6), 53-57.

Lu, L., Cai, R., Gursoy, D. (2020). Developing and validating a service robot integration willingness scale. International Journal of Hospitality Management, 80, 36-51.

Lu, Y., Ioannou, A., Tussyadiah, I., Li, S. (2019). Segmenting travelers based on responses to nudging for information disclosure. eReview of Tourism Research,17(3). Pp. 394-406

MacVaugh, J., Schiavone, F. (2010). Limits to the diffusion of innovation: A literature review and integrative model. European Journal of Innovation Management, 13(2), $197-$ 221.

Markard, J., Raven, R., Truffer, B. (2012). Sustainability transitions: An emerging field of research and its prospects. Research Policy, 41(6), 955-967.

Martelaro, N., Ju, W. (2018). Cybernetics and the design of the user experience of AI systems. Interactions, 25(6), 38-41.

McCarthy, J. (2007). What is artificial intelligence? http://jmc.stanford.edu/articles/whatisai/whatisai.pdf

McKinsey Global Institute (2017). Jobs lost, jobs gained: Workforce transitions in a time of automation.

https://www.mckinsey.com/ /media/McKinsey/Featured\%20Insights/Future\%20of\%200 rganizations/What $\% 20$ the $\% 20$ future $\% 20$ of $\% 20$ work $\% 20$ will $\% 20$ mean $\% 20$ for $\% 20$ jobs $\%$ 20skills\%20and\%20wages/MGI-Jobs-Lost-Jobs-Gained-Report-December-6-2017.ashx 
Melendez, S. (2018). A new border security app uses AI to flag suspicious people in seconds. https://www.fastcompany.com/40539812/new-unisys-tool-brings-machine-learning-toborder-security

Menzies, T., Pecheur, C. (2005). Verification and validation and artificial intelligence. Advances in Computers, 65, 153-201.

Millett, S. (2006). Futuring and visioning: complementary approaches to strategic decision making. Strategy \& Leadership, 34(3), 43-50.

Monroe, D. (2018). AI, explain yourself. Communications of the ACM, 61(11),11-13. Mori, M. (2012). The uncanny valley: The original essay by Masahiro Mori. IEEE Robotics and Automation, 19(2), 98-100.

Murphy, J., Gretzel, U., Pesonen, J. (2019). Marketing robot services in hospitality and tourism: the role of anthropomorphism. Journal of Travel \& Tourism Marketing, 36(7), 784-795.

Murphy, J.C., Hofacker, U., Gretzel, U. (2017). Dawning of the age of robots in hospitality and tourism: Challenges for teaching and research. European Journal of Tourism Research, 15, 104-111.

Nedelkoska, L., Quintini, G. (2018). Automation, skills use and training. OECD Social, Employment and Migration Working Papers, No. 202, OECD Publishing, Paris.

Nieto, D., Quesada-Arencibia, A., Garcia, C.R., Moreno-Diaz, R. (2014). A social robot in a tourist environment. In: Hervás, R., Lee, S., Nugent, C., Bravo, J. (Eds.), Ubiquitous Computing and Ambient Intelligence. Personalisation and User Adapted Services. Springer, Cham.

Nilsson, N.J. (2006). Human-level artificial intelligence? Be serious! AI Magazine, 26(4), 6875. 
Nomura, T., Kanda, T., Suzuki, T. (2006). Experimental investigation into influence of negative attitudes toward robots on human-robot interaction. AI and Society, 20(2), 138150.

Nomura, T., Suzuki, T., Kanda, T., Kato, K. (2006). Measurement of negative attitudes towards robots. Interaction Studies, 7(3), 437-454.

Özdemir, V., Hekim, N. (2018). Birth of Industry 5.0: Making sense of big data with artificial intelligence, "The Internet of Things" and next-generation technology policy. OMICS: A Journal of Integrative Biology, 22(1), n.p.

Pagallo, U. (2016). The impact of domestic robots on privacy and data protection, and the troubles with legal regulation by design. In: Gutwirth, S., Leenes, R., De Hert, P. (eds), Data Protection on the Move. Law, Governance and Technology Series, 24. Springer, Dordrecht.

Pham, Q.-C., Madhavan, R., Righetti, L., Smart, W., Chatila, R. (2018). The Impact of Robotics and Automation on Working Conditions and Employment. IEEE Robotics \& Automation Magazine, 25(2), 126-128.

Pinillos, R., Marcos, S., Feliz, R., Zalama, E., Gómez-García-Bermejo, J. (2016). Long-term assessment of a service robot in a hotel environment. Robotics and Autonomous Systems, 79, 40-57.

Pizam, A., Uriely, N., Reichel, A. (2000). The intensity of tourist-host social relationship and its effects on satisfaction and change of attitudes: the case of working tourists in Israel. Tourism Management, 21(4), 395-406.

Prentice, R.C., Witt, S.F., Wydenbach, E.G. (1994). The endearment behaviour of tourists through their interaction with the host community. Tourism Management, 15(2), 117-125.

Rajan, K., Saffiotti, A. (2017). Towards a science of integrated AI and Robotics. Artificial Intelligence, 247, 1-9. 
Rao, A.S. (2017). Responsible AI and national AI strategies. European Union Commission. https://ec.europa.eu/growth/toolsdatabases/dem/monitor/sites/default/files/4\%20International\%20initiatives\%20v3_0.pdf

Robotic Industries Association (2009). Robot terms and definitions.

https://www.robotics.org/product-catalog-detail.cfm/Robotic-IndustriesAssociation/Robot-Terms-and-Definitions/productid/2953

Rogers, E.M. (2003). Diffusion of Innovations. Free Press, New York.

Russell, S., Dewey, D., Tegmark, M. (2015). Research priorities for robust and beneficial artificial intelligence. AI Magazine, 36(4), n.p.

Russell,S., Norvig, P. (2010). Artificial Intelligence: A Modern Approach. Prentice Hall.

Safarzyńska, K., Frenken, K., van den Bergh, J.C.J.M. (2012). Evolutionary theorizing and modeling of sustainability transitions. Research Policy, 41(6), 1011-1024.

Sanfeliu, A., Punsola, A., Yoshimura, Y., Llacer, M.R., Gramunt, M.D. (2009). Legal challenges for networking robots deployment in European urban areas: The privacy issue. Workshop on Network Robots Systems, IEEE International Conference on Robotics and Automaton (ICRA2009), Kobe, Japan, May 12, 2009.

Schneider, C., Weinmann, M., vom Brocke, J. (2018). Digital Nudging-Guiding Choices by Using Interface Design. Communications of the ACM, 61(7), 67-73.

Schirner, G., Erdogmus, D., Chowdhury, K., Padir, T. (2013). The future of human-inthe-loop cyber-physical systems. Computer, 46(1), 36-45.

Schulze, E. (2019). Everything you need to know about the Fourth Industrial Revolution. https://www.cnbc.com/2019/01/16/fourth-industrial-revolution-explained-davos2019.html

Schwab, K. (2016). The Fourth Industrial Revolution. World Economic Forum/Penguin. 
Smith, A., Voß, J.-P., Grin, J. (2010). Innovation studies and sustainability transitions: The allure of the multi-level perspective and its challenges. Research Policy, 36(4), 435-448.

Szántó, Z. O. (2018). Social futuring - An analytical conceptual framework. Society and Economy, 40, 5-20.

Tarafdar, M., Gupta, A., Turel, O. (2013). The dark side of information technology use. Information Systems Journal, 23(3), 269-275.

Tarafdar, M., Tu, Q., Ragu-Nathan, T.S., Ragu-Nathan, B.S. (2011). Crossing to the dark side: examining creators, outcomes, and inhibitors of technostress. Communications of the ACM, 54(9), 113-120.

Thaler, R.H, Sunstein, C.R. (2008) Nudge: Improving Decisions about Health, Wealth, and Happiness. Yale University Press.

Thrun, S. (2004). Toward a framework for human-robot interaction. Human-Computer Interaction, 19(1-2), 9-24.

Tung, V.W.S., Law, R. (2017). The potential for tourism and hospitality experience research in human-robot interactions. International Journal of Contemporary Hospitality Management, 29(10), 2498-2513.

Tung, V.W.S., Au, N. (2018). Exploring customer experiences with robotics in hospitality. International Journal of Contemporary Hospitality Management, 30(7), 2680-2697.

Tuomi, A., Tussyadiah, I., Stienmetz, J. (2019). Leveraging LEGO® Serious Play® to embrace AI and robots in tourism. Annals of Tourism Research.

Turnheim, B., Berkhout, F., Geels, F., Hof, A., McMeekin, A., Nykvist, B., van Vuuren, D. (2015). Evaluating sustainability transitions pathways: Bridging analytical approaches to address governance challenges. Global Environmental Change, 35, 239-253, Tussyadiah, I.P. (2014). Toward a theoretical foundation for experience design in tourism. Journal of Travel Research, 53(5), 543-564. 
Tussyadiah, I.P. (2017). Technology and Behavioral Design in Tourism. In Fesenmaier, D.R., \& Xiang, Z. (Eds.), Design Science in Tourism. Springer, Cham.

Tussyadiah, I.P., Fesenmaier, D.R. (2009). Mediating tourist experiences: Access to places via shared videos. Annals of Tourism Research, 36(1), 24-40.

Tussyadiah, I., Li, S., Miller, G. (2019). Privacy protection in tourism: Where we are and where we should be heading for. In Pesonen, J., \& Neidhardt, J. (Eds.), Information and Communication Technologies in Tourism 2019. Springer.

Tussyadiah, I., Miller, G. (2019). Nudged by a robot: Responses to agency and feedback. Annals of Tourism Research.

Tussyadiah, I.P., Park, S. (2018). Consumer evaluation of hotel service robots. In Stangl, B., \& Pesonen, J. (Eds.), Information and Communication Technologies in Tourism 2018. Springer.

van Allen (2018). Prototyping ways to prototyping AI. Interactions, 25(6), 46-51.

Venkatesh, V., Davis, F. (2000). A theoretical extension of the technology acceptance model: four longitudinal field studies. Management Science, 46(2), 186-204.

Venkatesh, V., Morris, M.G., Davis, G.B., Davis, F.D. (2003). User acceptance of information technology: Toward a unified view. MIS Quarterly, 27(3), 425-478.

Venkatesh, V., Thong, J.Y.L., Xu, X. (2012). Consumer acceptance and use of information technology: Extending the Unified Theory of Acceptance and Use of Technology. MIS Quarterly, 36(1), 157-178.

Veruggio, G. (2010). Roboethics. IEEE Robotics \& Automation Magazine, 17, 105-109. Veruggio, G., Operto, F. (2008). Roboethics: Social and ethical implications of robotics. In Siciliano, B., Khatib, O. (eds) Springer Handbook of Robotics. Springer, Berlin.

Walters, M.L., Syrdal, D.S., Dautenhahn, K., te Boekhorst, R., Koay, K.L. (2008). Avoiding the uncanny valley: robot appearance, personality and consistency of behavior in an 
attention-seeking home scenario for a robot companion. Autonomous Robots, 24(2), 159178.

Whitmore, A., Agarwal, A., Xu, D. L. (2015). The Internet of Things-A survey of topics and trends. Information System Frontiers, 17(2), 261-274.

Wong, J.S. (2018). Design and fiction: Imagining civic AI. Interactions, 25(6), 42-45.

Yeoman, I., Mars, M. (2012). Robots, men and sex tourism. Futures, 44(4), 365-372.

Yu, Q., Yuan, C., Z. Fu, Z., Zhao, Y. (2012). An autonomous restaurant service robot with high positioning accuracy. Industrial Robot: An International Journal, 39(3), 271-281.

Zalama, E., Gómez-García-Bermejo, J., Marcos, S., Domínguez, S., Feliz, R., Pinillos, R., López, J. (2014). Sacarino, a Service Robot in a Hotel Environment. In: Armada, M., Sanfeliu, A., Ferre, M. (eds), ROBOT2013: First Iberian Robotics Conference. Advances in Intelligent Systems and Computing. Springer, Cham.

\section{Author's Bio}

Iis Tussyadiah (i.tussyadiah@surrey.ac.uk) is Professor of Intelligent Systems in Service and Head of Department of Hospitality in School of Hospitality and Tourism Management at University of Surrey. Her research interest lies in the intersection of digital technologies and tourism experiences. She investigates the application and implication of intelligent systems in the services sector to inform policy and business practice. 


\section{Automating Tourism: A Research Agenda}

\section{Statement of Contribution}

1. What is the contribution to knowledge, theory, policy or practice offered by the paper? This review paper provides an agenda for research around implementation of artificially intelligent automation in tourism based on literature review and trends in artificial intelligence tools and applications. This agenda contributes to ensuring a systematic production of knowledge in the field and, based on that, identification of needed policy interventions in anticipation of the impacts of intelligent automation. The paper suggests a range of theories from different disciplinary perspectives addressing research needs to design beneficial AI for individuals, the industry, the economy, and society in general. Due to the rapid development of AI systems and accelerated adoption of these technologies in tourism, this paper guides the tourism scientific community to tackle relevant global issues with impactful research.

2. How does the paper offer a social science perspective/approach?

This paper proposes an agenda for social science approaches to research the implementation of $\mathrm{AI}$ and its related technologies in tourism. It does so by contextualizing tourism as a social phenomenon and an economic activity. In recognizing the need to design beneficial AI, this paper argues that requirements for robust and beneficial AI should be based on socialbehavioral aspects of human-computer interactions underpinning the automated tourism experience. Key research priorities suggested in this paper include identifying factors influencing adoption on the levels of individuals, organizations, and society. Hence, basic disciplines in social sciences such as economics, behavioral science, and psychology, are where this research agenda is based on and expected to contribute to. 